\title{
Outcome of Tibio-talo-calcaneal Arthrodesis using Supracondylar Femoral Intramedullary Interlocking Nail
}

\author{
${ }^{1}$ S Hiranyakumar, ${ }^{2}$ Praneeth Revuri, ${ }^{3}$ Ashish D Shah
}

\begin{abstract}
Introduction: Tibiotalar arthritis of foot is a progressive pathology; if left untreated, patients experience excruciating pain at every step while walking/weight bearing. The treatment depends on whether the pain is to be managed conservatively or surgically. This article is intended for the description of a technique performing tibiotalocalcaneal arthrodesis (TTCA) using an indigenous femur supracondylar nail, an intramedullary fixation.
\end{abstract}

Materials and methods: This article contains a prospective study of 21 patients with a mean age of 46 years, males -13 and females -8 , who underwent TTCA with intramedullary fixation for the diagnoses of osteoarthrosis (6 patients), rheumatoid arthritis (6 patients), and arthritis secondary to avascular necrosis (AVN) of talus/trauma (9 patients), with a mean follow-up interval of 22 months.

Results: Out of 21 patients, $96.55 \%$ union rate was achieved at a mean time to union of 16 weeks, with one patient (3.45\%) going for delayed union.

Conclusion: Intramedullary nailing is an excellent method of fixation for TTCA in the appropriately selected patients. Using an indigenous supracondylar femoral nail is a cost-effective method, and this gave equivalent results as that of other intramedullary nails in properly selected patients.

Keywords: Intramedullary fixation, Supracondylar femoral nail, Tibiotalocalcaneal arthrodesis.

How to cite this article: Hiranyakumar S, Revuri P, Shah AD. Outcome of Tibio-talo-calcaneal Arthrodesis using Supracondylar Femoral Intramedullary Interlocking Nail. J Foot Ankle Surg (Asia-Pacific) 2017;4(1):23-29.

\section{Source of support: Nil}

Conflict of interest: None

\section{INTRODUCTION}

Ankle joint and subtalar joints are two crucial components of the ankle-hindfoot complex for the normal activity

\footnotetext{
${ }^{1}$ Professor and Unit Chief, ${ }^{2}$ Assistant Professor, ${ }^{3}$ Consultant and Head

${ }^{1,2}$ Department of Orthopaedics, Vydehi Institute of Medical Sciences \& Research Centre, Bengaluru, Karnataka, India

${ }^{3}$ Department of Foot and Ankle Surgery, UAB HospitalHighlands, Birmingham, Alabama, USA

Corresponding Author: Praneeth Revuri, Assistant Professor Department of Orthopaedics, Vydehi Institute of Medical Sciences \& Research Centre, Bengaluru, Karnataka, India Phone: +918028413381, e-mail: praneeth.revuri@gmail.com
}

and flexibility around the ankle area for weight bearing, walking, and other strenuous activities. Ankle and subtalar joints can be damaged due to various causes like injury, developmental disorders, inflammatory disorders, infective disorders, or chronic tendon dysfunction at ankle joint or hindfoot. This can cause severe pain, deformity, and walking dysfunction. For those patients who do not obtain satisfactory efficacy from conservative treatment, surgical treatment might relieve pain and restore function. Tibiotalar joint replacement plus fusion of subtalar joint was previously proposed. ${ }^{1}$ However, this surgery is complicated and has uncertain longterm outcomes. Tibiotalocalcaneal arthrodesis (TTCA) showed favorable outcomes and restored normal daily life function and is still the gold standard surgery for end-stage disease of the tibiotalar and subtalar joints. ${ }^{2}$ The TTCA was first introduced by Lexer in $1906 .{ }^{3,4}$ With the development of new implants and improvement of surgical techniques, the fusion rate of TTCA gradually increased and the complication rate decreased. ${ }^{5,6}$ Surgical fixation materials used in TTCA include screws, external fixator, and angle plate. However, TTCA may be achieved through several fixation methods: Cancellous screw fixation, angle plate fixation, retrograde intramedullary nail fixation, and locking plate fixation.

Many techniques, approaches, and appliances have been developed to achieve ankle and hindfoot arthrodesis. $^{7-16}$ The purpose of this article is to describe instrumentation to establish TTCA. This is a prospective study and presents the results of this type of fusion, employing an older technique with indigenously available supracondylar femoral nail, placed retrograde combined with arthrotomy and debridement of the ankle. The femoral intramedullary supracondylar nail is placed transcalcaneally through the talus into the tibia and locked proximal and distal to these joints.

The significance of this series lies in the fact that a method of hindfoot arthrodesis, first described more than 40 years ago by Kuntscher, may successfully be employed even today with the availability of an affordable fixation device, an indigenous supracondylar femoral nail.

\section{MATERIALS AND METHODS}

Patients aged between 45 and 57 years (mean age of 48 years), males -13 and females -8 , attending the 
Orthopaedic Department of Vydehi Institute of Medical Sciences \& Research Centre, Bengaluru, India, from June 2013 to June 2016, with primary osteoarthritis, rheumatoid arthritis, and posttraumatic arthritis of the ankle joint, with failed conservative management, were selected for this prospective study.

The indications for a TTCA include avascular necrosis of the talus, osteoarthrosis, the sequelae of trauma, severe deformity of neglected adult clubfoot and neuromuscular disease, rheumatoid arthritis, and tubercular arthritis.

Contraindications to this technique include a dysvascular extremity or one that has a severe active infection. Also to be avoided is a plantar approach in the patient who has an insufficient plantar weight-bearing surface of padding. Moderate-to-severe and fixed deformity of the ankle, hindfoot, and distal tibia are also relative contraindications for intramedullary nailing and arthrodesis.

Patients not fit for the surgery due to anesthetic or other comorbidities were excluded.

Preoperative visual analog scale (VAS) score was assessed to be 6 to 8 , with 7 as average. Preoperative American Orthopaedic Foot and Ankle Society (AOFAS) hindfoot score was 26 to 57, with 41.5 as average (100 being normal).

\section{Hardware}

We used indigenous intramedullary supracondylar interlocking femoral nail manufactured by Sharma Surgicals, Ltd., India. The intramedullary supracondylar femoral nail is a fully cannulated, stainless steel, closed section nail with a 11,12 , or $13 \mathrm{~mm}$ outer diameter and lengths of 20 or $25 \mathrm{~cm}$. The first two distal holes are located 15 and $30 \mathrm{~mm}$ from the driving end for good calcaneal and talar fixation. The transfixing holes are locked with $5 \mathrm{~mm}$ fully threaded screws, and numerous interlocking holes are available proximal to the ankle for proximal fixation (Fig. 1).

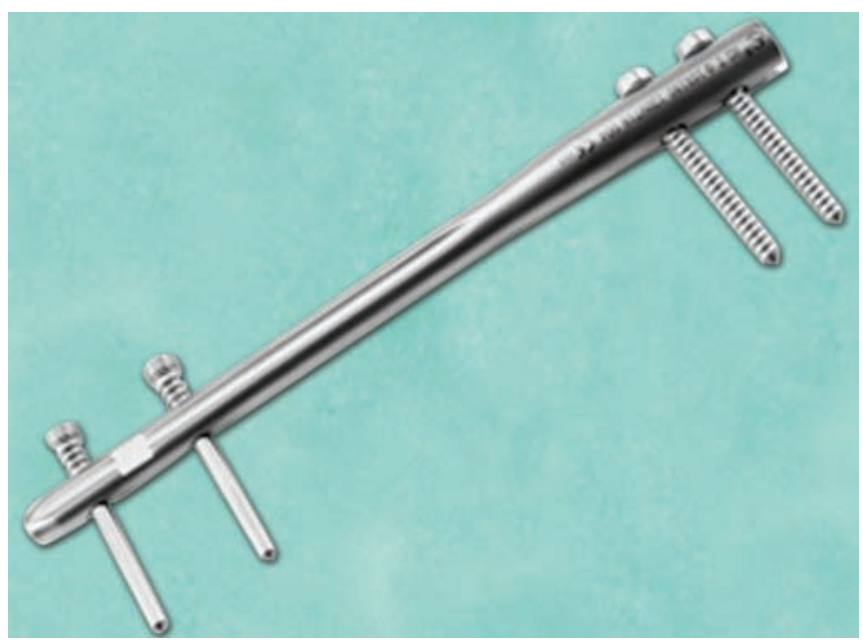

Fig. 1: Design of supracondylar interlocking nail

\section{Surgical Technique}

The patient is positioned supine on a radiolucent operating table with a well-padded bump under the ipsilateral buttock in order to internally rotate the involved extremity. We place another bump under the heel, so that intraoperative cross-table fluoroscopic imaging is facilitated. General or spinal anesthesia is usually used, and a thigh pneumatic tourniquet greatly facilitates plantar dissection. We use intraoperative C-arm fluoroscopy.

An extended lateral approach " $L$ "-shaped incision (Fig. 2) starting $6 \mathrm{~cm}$ proximally to lateral malleolus extending on the fibula until the tip of lateral malleolus curving distally to third ray of the foot was made. Ankle joint is exposed by excising the lateral malleolus using oscillating saw. The ankle and subtalar joints are prepared and for the cases with AVN talus, afterpreparation bonegraft (from the excised lateral malleolus) is used.

A longitudinal plantar approach is used, placing the incision slightly lateral to the midline, especially in the patient with significant valgus of the hindfoot and ankle. After the incision is made, blunt dissection is taken down to the plantar fascia, which is split longitudinally. The intrinsic muscles are swept laterally, and the neurovascular bundle is identified at the medial portion of the wound. A sharp awl is used to make a plantar calcaneal corticotomy, and the subtalar and tibiotalar articular surfaces are usually opened up with the use of a cannulated drill over its threaded guide wire. This opens up the tibiotalocalcaneal canal enough that a spade-tipped guide wire can be passed into the tibial medullary canal more readily. A series of progressively larger flexible reamers are used to open the tibiotalocalcaneal canal, reaming to a full to $1 \mathrm{~mm}$ diameter larger than the anticipated nail outside diameter.

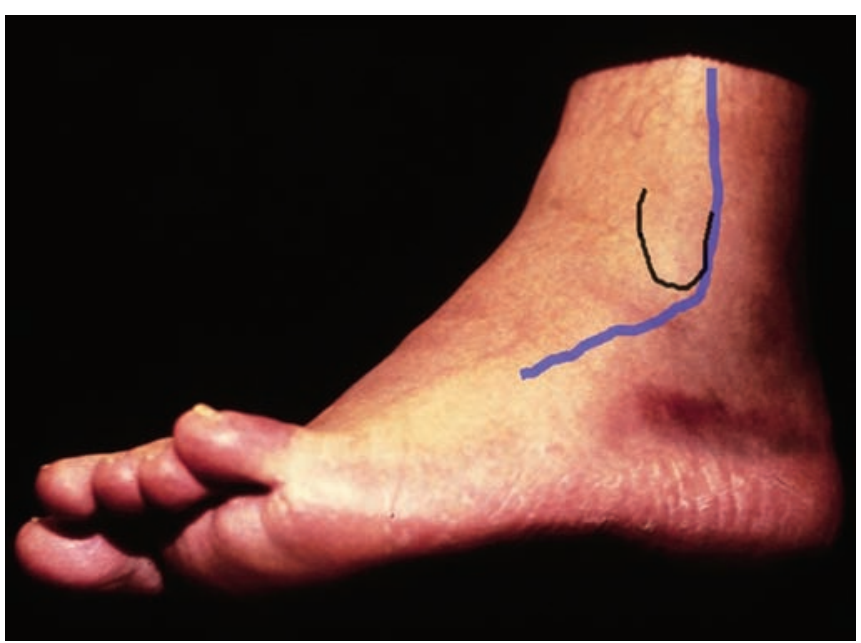

Fig. 2: Lateral approach to the ankle and subtalar joint 


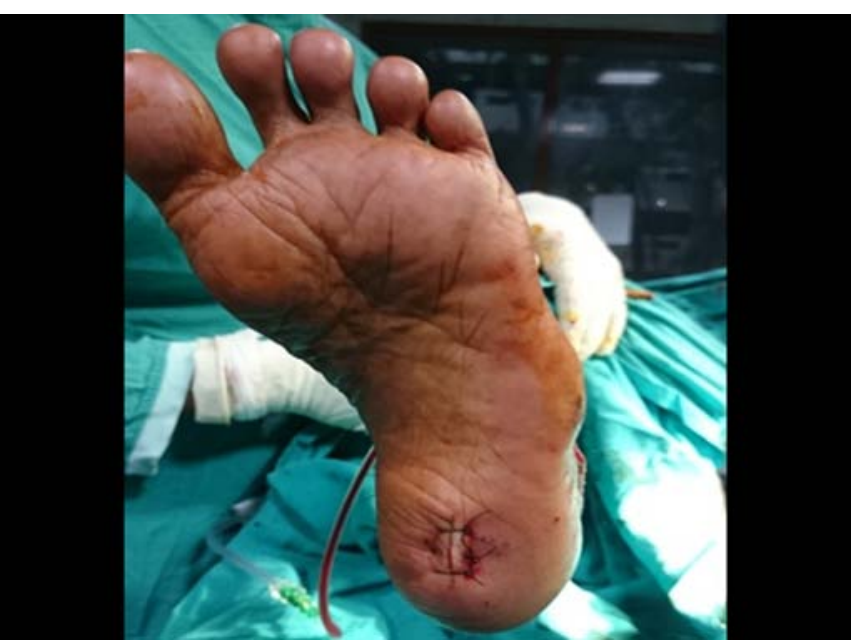

Fig. 3: Plantar aspect entry point of the nail

The nail is attached to its alignment guide after noting the appropriate bow, and which holes are to be used for interlocking once the nail is inserted. The nail is slightly internally rotated, so that when the screws are inserted from lateral to medial, they will pass into the tibia, clearing the fibula. The foot is to be maintained in neutral or $0^{\circ}$ plantar flexion, 0 to $5^{\circ}$ valgus, and 10 to $15^{\circ}$ of external rotation.

The nail is quite readily inserted manually and then impacted on the plantar aspect of the hindfoot (Fig. 3). The distal aspect of the nail is countersunk within the os calcis, and usually the distal two screws are inserted for interlocking first. This allows good purchase of the foot, and then further impaction can be done, giving compression across the arthrodesis site before the nail is interlocked in the tibia. The interlocking screws are inserted from lateral to medial, using the interlocking alignment device, and when necessary, intraoperative fluoroscopy (Fig. 4); wound was closed with nonadsorbable suture material (ethylon 2.0) with drain placed in situ (Fig. 5). Below-knee slab was applied for the immobilization.

We also used anterolateral approach without excision of the lateral malleolus (Figs 6A to $\mathrm{H}$ ).

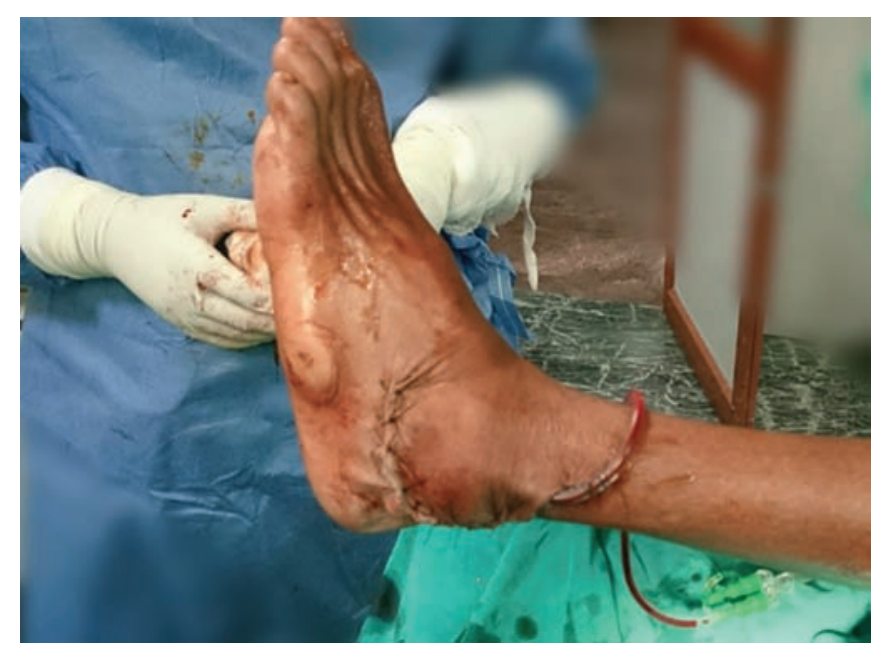

Fig. 5: Incision closure using ethylon suturing

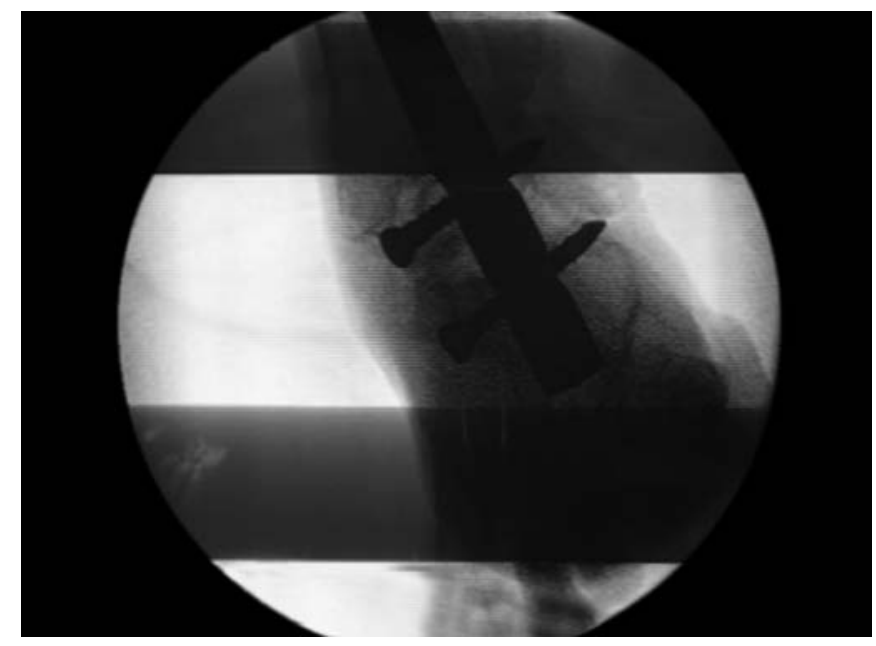

Fig. 4: Confirmation of the nail placement under fluoroscopy

Intraoperative blood loss was around 500 to $750 \mathrm{~mL}$ per case. There was minimal fluoroscopic exposure to assess the alignment of nail and position of arthrodesis.

In the postoperative period strict limb elevation with below-knee slab immobilization was done for 48 to 72 hours. Intravenous antibiotics - one dose pre-op or postoperative 72 hours - were used and later converted to oral prophylactic dosage. Suture removal was done on the 15 th postoperative day, and slab was converted to belowknee cast and advised with nonweight bearing ambulation for 4 to 6 weeks. After the follow-up X-ray, the patient was made to toe touch weight bearing and gradually increased to full weight bearing over a period of 3 weeks.

At the 6 months follow-up, postoperative VAS score was 0.5 to 3 and postoperative AOFAS hindfoot score was 62 to 86 (Table 1). The pre-op and follow-up X-rays of few cases are depicted in Figures 7A to C to 11.

\section{RESULTS}

Twenty-one patients ( 13 males and 8 females) with a mean age of 48 years underwent TTCA with intramedullary fixation for diagnoses of osteoarthrosis (6 patients), rheumatoid arthritis (6 patients), and arthritis secondary to AVN of talus (9 patient). With a mean follow-up interval of 22 months (7-36 months), a 96.55\% union rate was achieved at a mean time to union of 16 weeks

\section{Complications}

Four patients had wound-healing issues at the operative site, three out of them healed by secondary intention,

Table 1: Preoperative and postoperative study of VAS and AOFAS hindfoot score

\begin{tabular}{lll}
\hline Scale & Preoperative (0-10) & Postoperative \\
\hline VAS score & $6-8$ & $1.7(0.5-3)$ \\
AOFAS Hindfoot score & $26-57$ & $67(62-86)$ \\
\hline
\end{tabular}




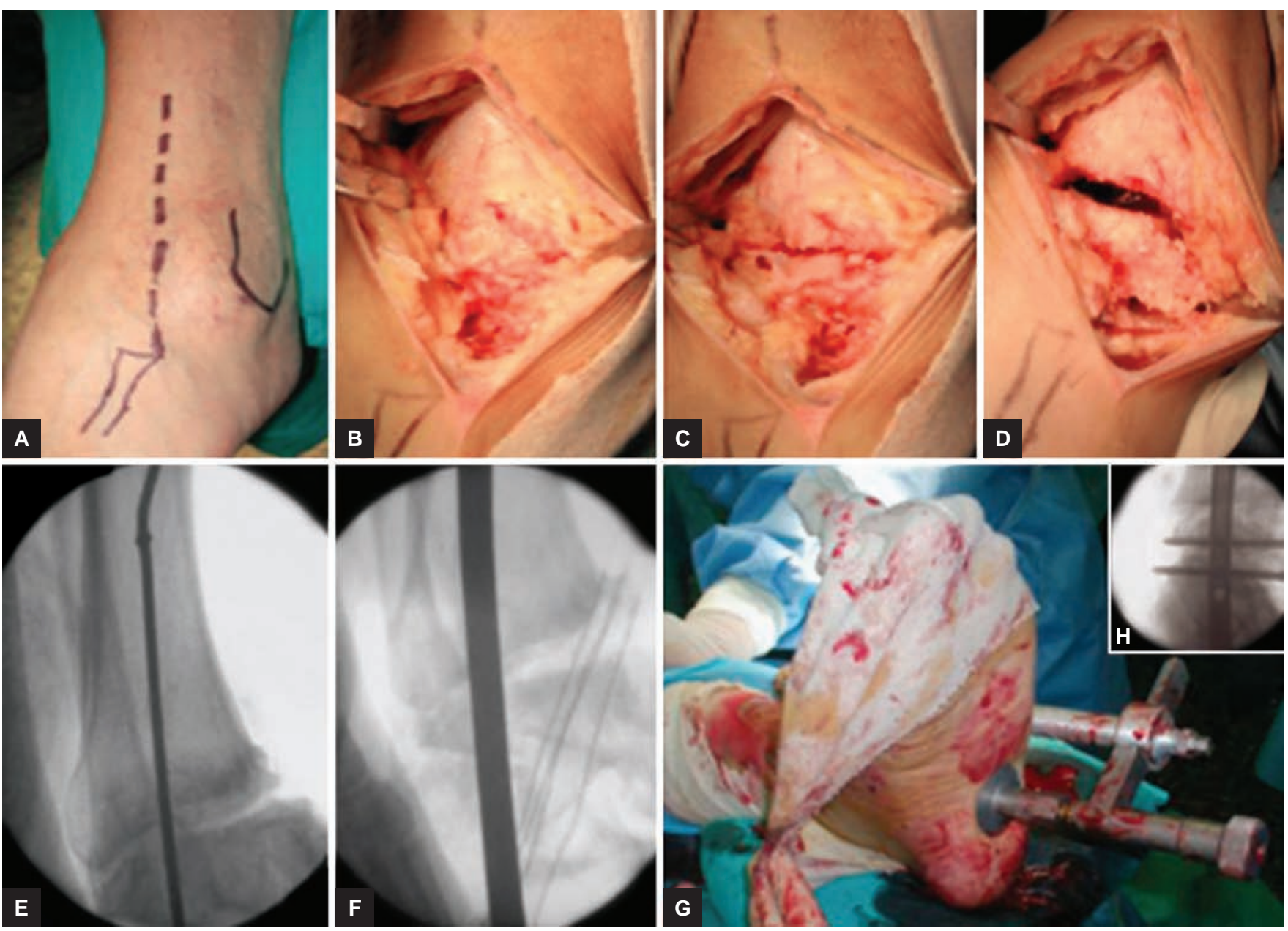

Figs $6 \mathrm{~A}$ to $\mathrm{H}$ : Anterolateral approach to ankle joint and nail fixation transcalcaneal with the aid of fluoroscopy

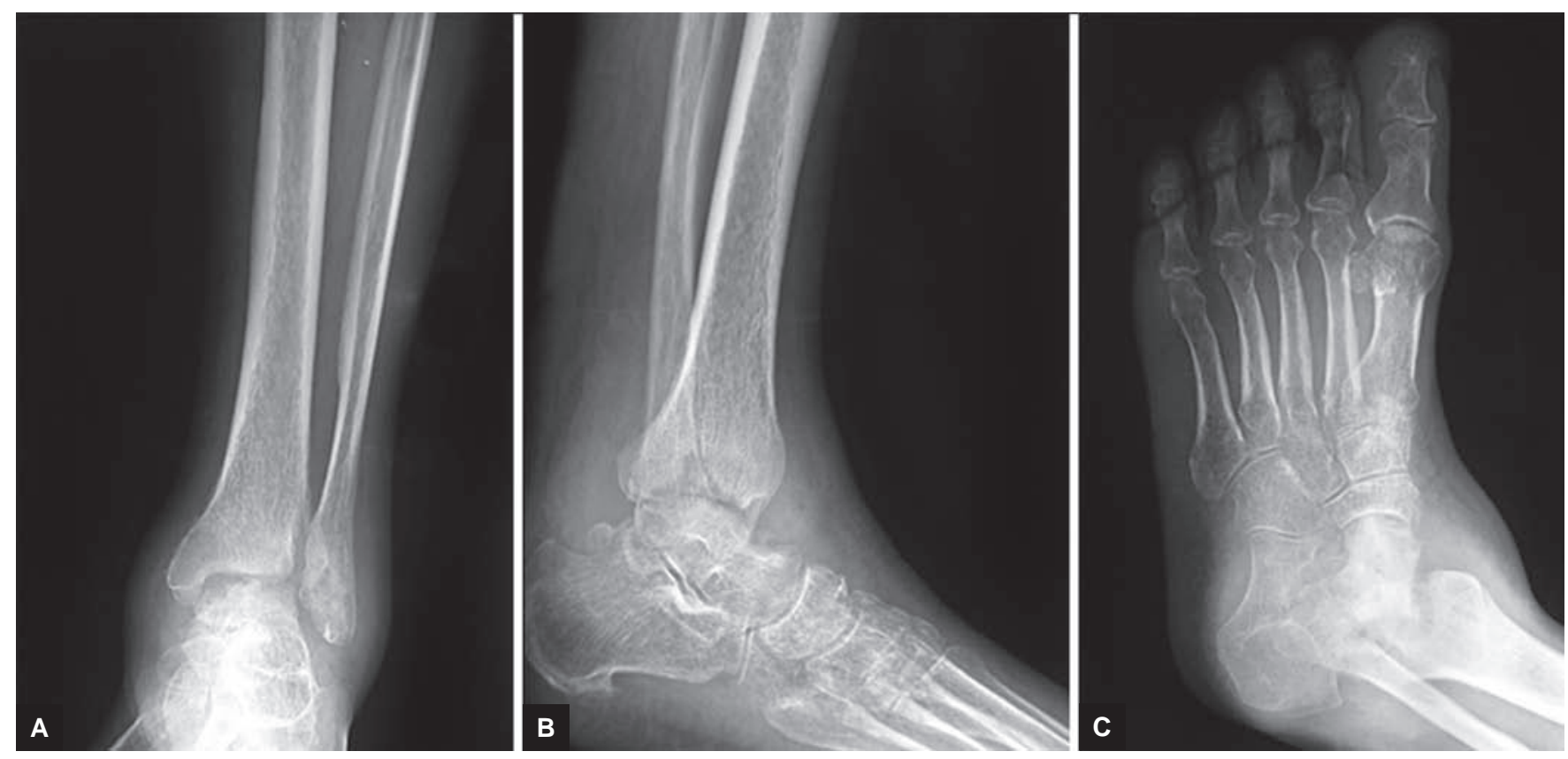

Figs 7A to C: Preoperative X-rays showing ankle and subtalar arthritis (case 1)

whereas one patient required debridement and split skin grafting.

One patient developed discharge and wound over the dorsum of the foot after 8 months postoperative (uncontrolled diabetes) (Fig. 12). Radiographs revealed complete fusion has been achieved, hence, implant removal was done; wound healed well without further complications. 


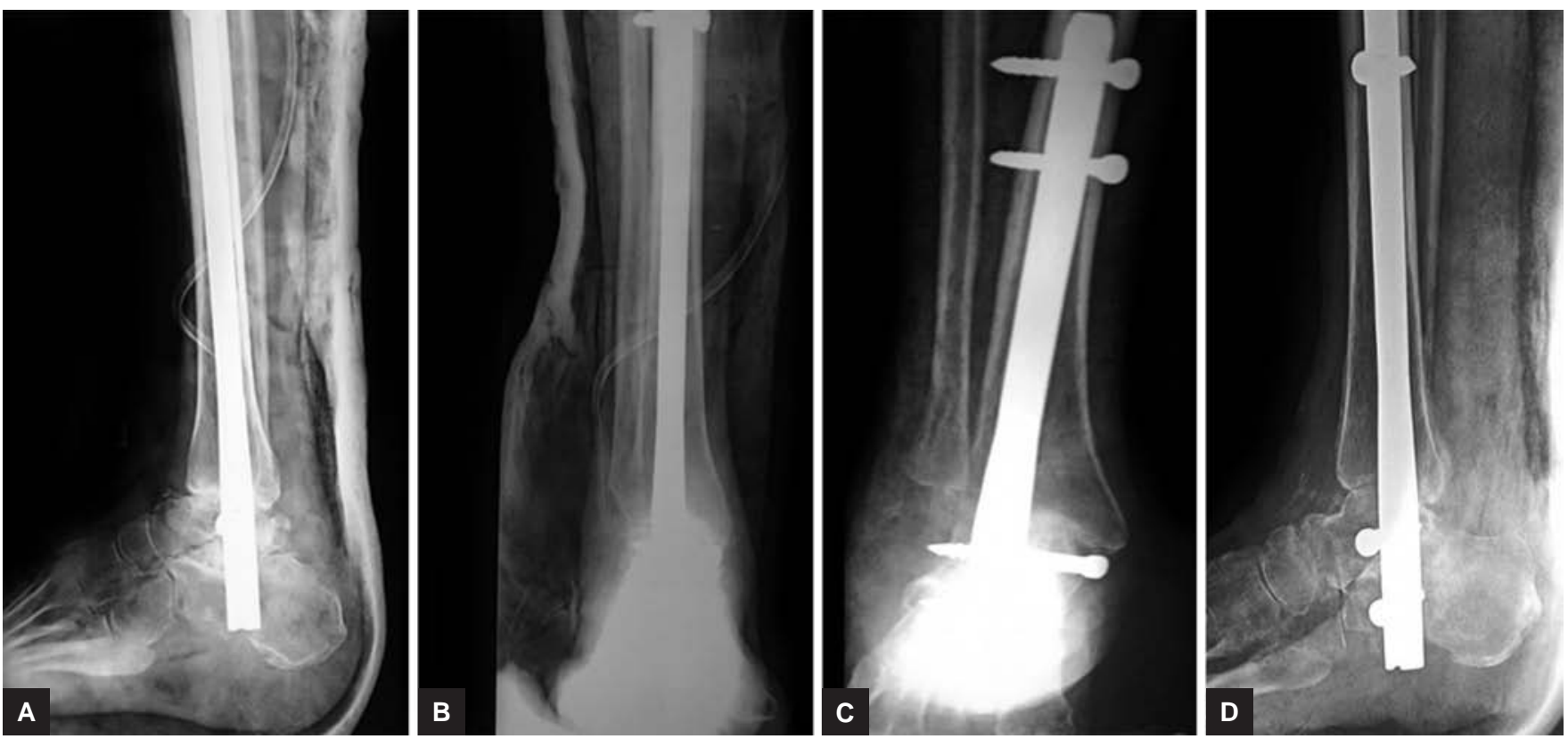

Figs 8A to D: Immediate and postoperative X-ray showing supracondylar femoral nail in situ, 3 months follow-up X-ray anteroposterior of ankle showing attempt of fusion (case 1)

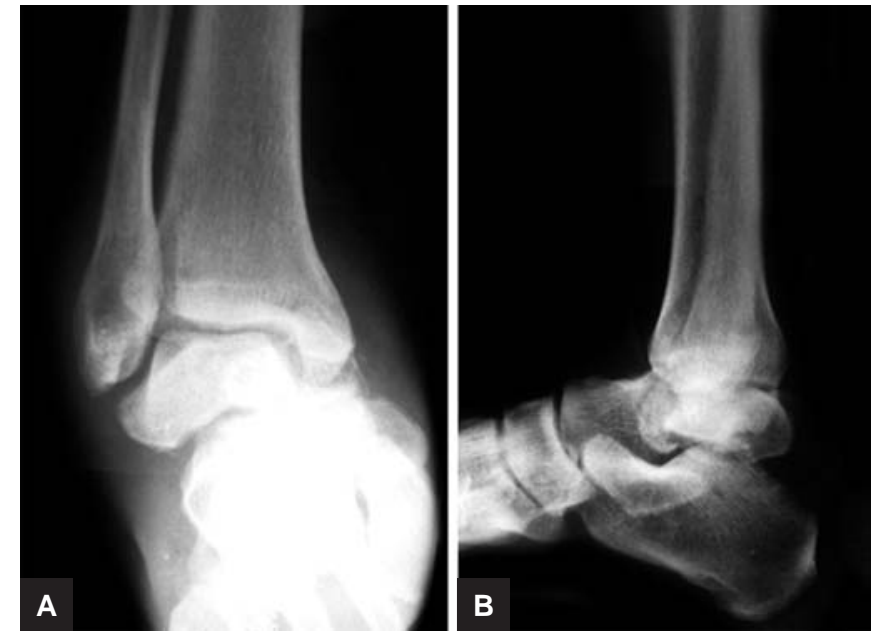

Figs 9A and B: Preoperative X-ray of ankle shows ankle and subtalar arthritis with subluxation (case 2)

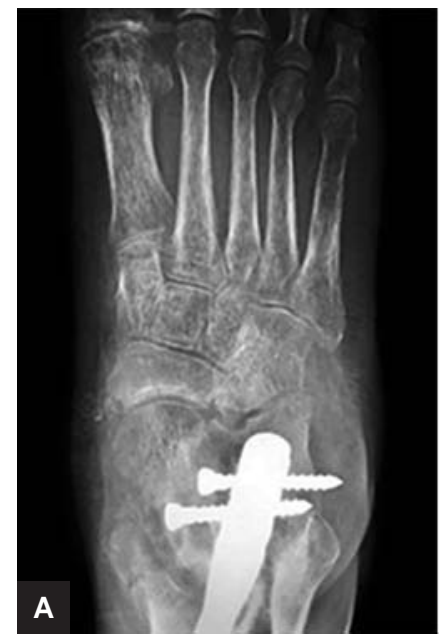

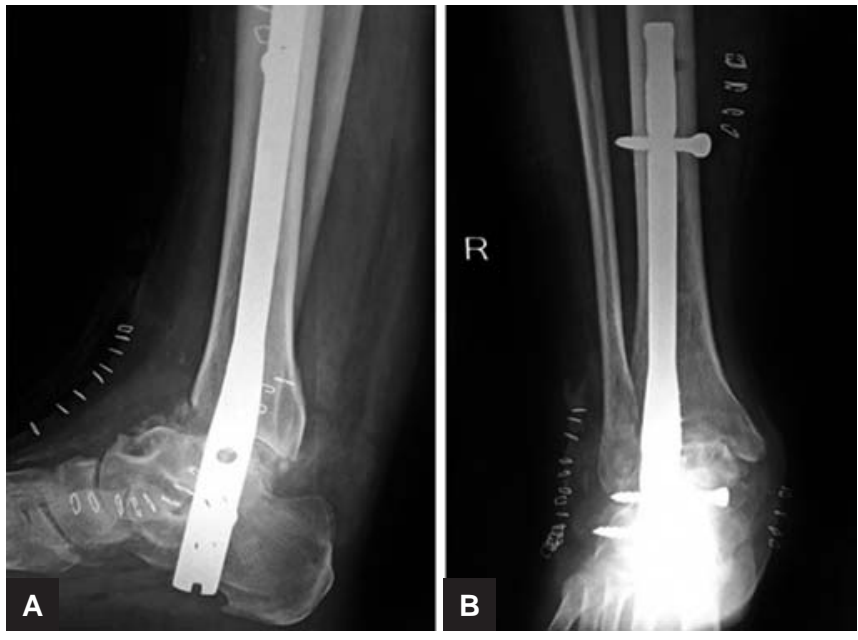

Figs 10A and B: Postoperative X-ray of ankle depicting supracondylar femoral nail in situ (case 2)

Figs 11A to C: X-rays of achieved tibiotalar arthrodesis and postimplant removal (case 3) 


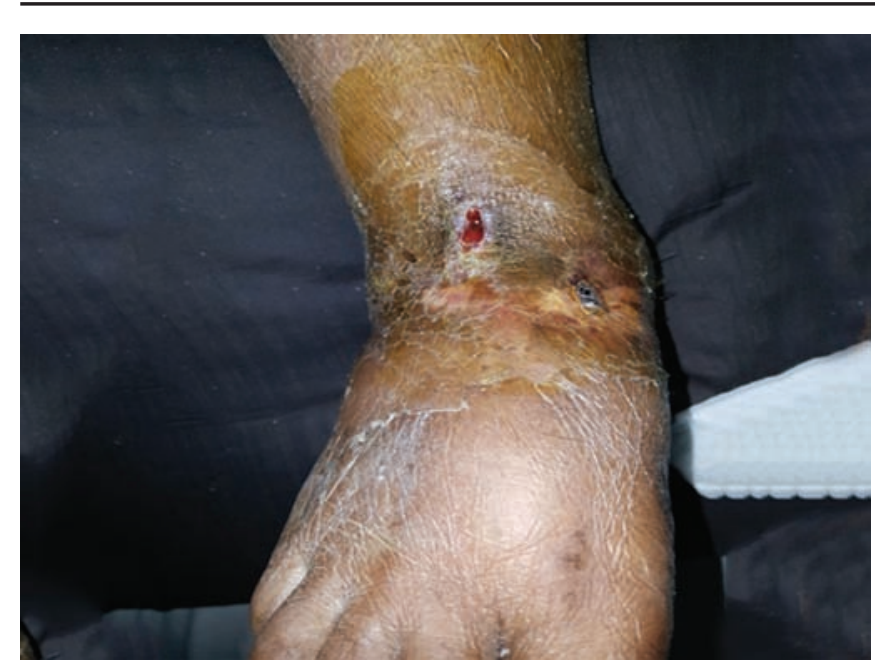

Fig. 12: Wound over the anterior aspect of ankle joint

One patient had delayed union at ankle joint after 8 months. Patient was operated with dynamization and bone grafting, followed by successful union.

Arthrodesis is a salvage procedure; hence, some of the difficulties encountered by the patients in this study were

- Limb shortening of 2 to $3 \mathrm{~cm}$ (compensated by shoe raise)

- Difficulty in squatting and using Indian toilets

- Difficulty in sitting cross-legged

- Difficulty in running.

\section{DISCUSSION}

The goals of ankle arthrodesis are relief of pain and deformity and the development of a solid fusion. Numerous techniques and instrumentation devices have been described and created to achieve these goals. The authors believe that intramedullary nailing is an excellent method of fixation for TTCA.

In a German text entitled "ThePractice of Intramedullary Nailing," published in the 1940s and 1950s, Küntscher ${ }^{10}$ described a method of combined arthrodesis of the ankle and subtalar joints. ${ }^{4}$ He employed a technique of closed medullary nailing with a conical nail inserted over a guide pin through the sole of the foot. He felt that extensive destruction of the joint and nailing should be done simultaneously. He used a 12 to $14 \mathrm{~mm}$ nail to achieve an interference fit, and no locking of the nail was done. The patients were kept at bed rest for 3 weeks and then ambulated in plaster.

In 1979, Tomeno and Danan ${ }^{15}$ presented 45 pan arthrodeses using various fixation techniques, but with a fairly high infection rate. These authors had an $80 \%$ consolidation rate. Russotti et $\mathrm{al}^{14}$ reported on 21 tibiotalocalcaneal arthrodeses employing Steinmann pins and external fixation. They had radiographic union in $86 \%$ with satisfactory results in $75 \%$ employing a posterior Achilles-splitting approach.
Papa and Myerson ${ }^{12}$ published a series of 21 pantalar and tibiotalocalcaneal arthrodeses for osteoarthrosis. They achieved an $86 \%$ fusion rate using a transfibular approach with cannulated screws. These authors also had two patients who underwent TTCA in a neuropathic fusion series. ${ }^{11}$ Both these patients fused in under 5 months using a cannulated screw technique.

Drs Johnson and Gehrke ${ }^{8}$ returned to using an intramedullary nail for tibiotalocalcaneal fusion in a presentation given at the 1993 Summer Meeting of the AOFAS. They positioned the patient prone and used an Achilles-splitting approach, but they claimed that the technology in using the nail was more involved than other established techniques, and that the longterm results were not known as yet. The Richards supracondylar nail was initially designed to aid in the fixation of supracondylar femur fractures and is available in a variety of lengths and diameters. A special order ankle fusion nail, in which some of the locking holes that would be present near the arthrodesis sites are eliminated, is now under investigation.

As described earlier, we have modified and simplified the technique initially described by Dr Johnson and Gehrke. $^{8}$

The results of this series would indicate that intramedullary nailing is a solid method of fixation for TTCA in the appropriately selected patients. They achieved an overall union rate of $82 \%$ at a mean time to union of 14 weeks in a large series that included patients undergoing TTCA for a variety of indications. They had a symptomatic nonunion rate of $12 \%$.

Dr Gavaskar and Chowdary's ${ }^{17}$ study of 7 patients pointed that "all patients achieved fusion in a mean of 13 weeks and regained their preoperative level of independence." No patient had a relapse, major complications, or hardware failure. At postoperative year one, the mean foot and ankle outcome score (FAOS) for pain improved to 85 from 26, whereas the mean FAOS for quality-of-life improved to 60 from 5. Concluding TTCA using a supracondylar femoral nail, combined with debridement and multidrug therapy, enabled a reliable one-stage solution for advanced osteoarticular tuberculosis and early return to function.

The study in Spain conducted in 2009 stated that mean follow-up was 32 months (7-61). Overall results were highly satisfactory, with a mean score of 88.6 points. Healing occurred after a mean of 18.3 weeks. The most frequent complications were an instance of mild skin necrosis at the edges of the wound, a plantar ulcer that resolved with conservative treatment, and a leg length discrepancy of $2 \mathrm{~cm}$. It was concluded that TTCA with a retrograde nail can be an excellent technique for patients with severe involvement of the tibiotalar and subtalar 
Table 2: Comparative tabulation of other similar studies

\begin{tabular}{llllllll}
\hline & $\begin{array}{l}\text { Number of } \\
\text { patients }\end{array}$ & Age & $\begin{array}{l}\text { Follow-up } \\
\text { (months) }\end{array}$ & Union rate (\%) & $\begin{array}{l}\text { Mean time for } \\
\text { consolidation } \\
\text { (weeks) }\end{array}$ & $\begin{array}{l}\text { American } \\
\text { orthopaedic foot } \\
\text { and ankle society }\end{array}$ & $\begin{array}{l}\text { Visual analog } \\
\text { scale }\end{array}$ \\
\hline Mendicino et al $^{3}$ & 19 & $56(33-81)$ & $56(33-81)$ & 95 & 17 & - & - \\
Hammett et al $^{19}$ & 47 & $57.1(25-81)$ & $34(8-37)$ & 87 & 17 & 63 & - \\
Niinimaki et al $^{5}$ & 34 & $57(25-77)$ & $24(6-43)$ & 76 & 16 & - & 1.9 \\
Smith et al $^{18}$ & 10 & $60.6(48-78)$ & $14.7(12-18)$ & 80 & - & 69 & 2 \\
Chou et al $^{21}$ & 37 & $53(19-79)$ & $26(12-168)$ & 86 & 19 & 66 & - \\
This study & 21 & $48(45-57)$ & $22(7-36)$ & 96.55 & 16 & 67 & $1.7(0.5-3.0)$ \\
\hline
\end{tabular}

joints who are unresponsive to conservative treatment. It can also be used as salvage surgery in previously failed arthrodesis procedures. ${ }^{18}$

A comparative analysis with the similar type of studies has been illustrated in Table $2 .^{18-21}$

\section{CONCLUSION}

The use of indigenous retrograde supracondylar femoral nail is an excellent method for Tibiotalocalcaneal fusion for patients with severe tibiotalar arthritis in achieving excellent results in fusion as well as relieving pain in patients who had failed with conservative management. The use of indigenous supracondylar femoral interlocking nail is very cost-effective and achieved similar results as compared with that of other studies.

\section{REFERENCES}

1. Kim BS, Knupp M, Zwicky L, Lee JW, Hintermann B. Total ankle replacement in association with hindfoot fusion: outcome and complications. J Bone Joint Surg Br 2010 Nov;92(11):1540-1547.

2. Nihal A, Gellman RE, Embil JM, Trepman E. Ankle arthrodesis. Foot Ankle Surg 2008;14(1):1-10.

3. Mendicino RW, Catanzariti AR, Saltrick KR, Dombek MF, Tullis BL, Statler TK, Johnson BM. Tibiotalocalcaneal arthrodesis with retrograde intramedullary nailing. J Foot Ankle Surg 2004 Mar-Apr;43(2):82-86.

4. Quill GE. Tibiotalocalcaneal arthrodesis. Tech Orthop 1996 Fall;11(3):269-273.

5. Niinimäki TT, Klemola TM, Leppilahti JI. Tibiotalocalcaneal arthrodesis with a compressive retrograde intramedullary nail: a report of 34 consecutive patients. Foot Ankle Int 2007 Apr;28(4):431-434.

6. Haaker R, Kohja EY, Wojciechowski M, Gruber G. Tibiotalo-calcaneal arthrodesis by a retrograde intramedullary nail. Ortop Traumatol Rehabil 2010 May-Jun;12(3):245-249.

7. Barrett GR, Meyer LC, Bray EW, Taylor RG, Kolb FJ. Pantalar arthrodesis: a long-term follow-up. Foot Ankle 1981 Mar;1(5): 279-283.
8. Johnson KA, Gehrke JC. Intramedullary fixation for ankle arthrodesis. Proceedings of the Annual Summer Meeting of the American Orthopaedic Foot and Ankle Society. 1993.

9. Kitaoka HB, Romness DW. Arthrodesis for failed ankle arthroplasty. J Arthroplasty 1992 Sep;7(3):722-784.

10. Küntscher G. Praxis der marknagelung. Basel, Karger: Reprint by Karger; 1986. p. 251-271.

11. Papa J, Myerson M, Girard P. Salvage, with arthrodesis, in intractable diabetic neuropathic arthropathy of the foot and ankle. J Bone Joint Surg Am 1993 Jul;75(7):1056-1066.

12. Papa JA, Myerson MS. Pantalar and tibiotalocalcaneal arthrodesis for post-traumatic osteoarthrosis of the ankle and hindfoot. J Bone Joint Surg Am 1992 Aug;74(7):1042-1049.

13. Reckling FW. Early tibiocalcaneal fusion in the treatment of severe injuries of the talus. J Trauma 1972 May;12(5): 390-396.

14. Russotti GM, Johnson KA, Cass JR. Tibiotalocalcaneal arthrodesis for arthritis and deformity of the hind part of the foot. J Bone Joint Surg Am 1988 Oct;70(9):1304-1307.

15. Tomeno B, Danan JP. Pan arthrodesis of the rear of the foot. Rev Chir Orthop 1979;65:433-439.

16. Vahvanen V. Arthrodesis of the TC or pantalar joints in rheumatoid arthritis. Acta Orthop Scand 1969;40(5): 642-652.

17. Gavaskar AS, Chowdary N. Tibiotalocalcaneal arthrodesis using a supracondylar femoral nail for advanced tuberculous arthritis of the ankle. J Orthop Surg 2009 Dec;17(3): 321-324.

18. Smith JW, Moore TJ, Fleming S, Pochatko D, Principe R. Tibiotalocalcaneal arthrodesis with a retrograde intramedullary nail. Foot Ankle Int 2007;19(16):433-436.

19. Hammett R, HeppleS, Forster B, Winson I. Tibiotalocalcaneal (hindfoot) arthrodesis by retrograde intramedullary nailing using a curved locking nail. The results of 52 procedures. Foot Ankle Int 2005 Oct;26(10):810-815.

20. Sánchez Gómez P, Salinas Gilabert JE, Lajara Marco F, Lozano Requena JA. Tibiotalocalcaneal arthrodesis with a retrograde intramedullary nail. Rev Esp Cir Ortop Traumatol 2010;54(1):50-58.

21. Chou LB, Mann RA, Yaszay B, Graves SC, McPeake WT 3rd, Dreeben SM, Horton GA, Katcherian DA, Clanton TO, Miller RA, et al. Tibiotalocalcaneal arthrodesis. Foot Ankle Int 2000 Oct;21(10):804-808. 